\title{
Phaeohyphomycosis Due to Exophiala oligosperma in an Immunocompromised Host
}

HIROFUMI NISHIKAWA ¿, MD; YOSHINORI TANIGUCHIㄹ, MD; Department of Endocrinology, Metabolism, Nephrology and Rheumatology, Kochi Medical School Hospital, Nankoku, Kochi, Japan. Address correspondence to Dr. Y. Taniguchi, Department of Endocrinology, Metabolism, Nephrology and Rheumatology, Kochi Medical School Hospital, Kochi University, Kohasu, Oko-cho, Nankoku, Kochi 783-8505, Japan. E-mail: yoshii.tan@ gmail.com. The authors obtained the patient's written informed consent to publish the material and received ethics board approval by the institutional review boards of Kochi Medical School Hospital (approval no. 22-78). J Rheumatol 2019;46:652; doi:10.3899/jrheum.180774

Exophiala is a genus of saprophytic fungi that have been isolated from hot, humid, and oligotrophic environments. Phaeohyphomycosis encompasses a heterogeneous group of infections caused by dematiaceous fungi including Exophiala species in immunocompromised hosts, in whom they could cause infection through a minor scratch ${ }^{1,2,3}$.

An 86-year-old woman with adult-onset Still disease, who was under clinical remission with prednisolone and tacrolimus, presented with a 2-month history of fever. She had often scratched her forearms in the past year. Physical examination revealed cutaneous granulomatous lesions, indicating abscesses, on the right forearm (Figure 1A). Blood examination showed elevated C-reactive protein (CRP; 0.53 $\mathrm{mg} / \mathrm{dl})$ and $\beta$-D-glucan $(60.8 \mathrm{pg} / \mathrm{ml})$, a fungal cell wall polysaccharide that can be released into the peripheral blood in patients with fungal infections. Pus samples were cultured, producing olivaceous black colonies in 5 days (Figure 1B). The fungal strain was identified as Exophiala oligosperma based on rDNA sequence analysis. The isolate grew at temperatures $<35^{\circ} \mathrm{C}$ but failed to grow at $>37^{\circ} \mathrm{C}$, suggesting that a characteristic feature of this fungal infection is that it is cultured at low temperatures. The patient received drainage, local hyperthermia, and antifungal therapy (itraconazole and flucytosine). Subsequently, CRP and
$\beta$-D-glucan levels normalized, and skin lesions resolved completely. Exophiala species are generally treated with azoles ${ }^{4}$. Although immunosuppression by tacrolimus was a possible infective factor in this case, synergistic effects of tacrolimus and azoles are also often reported ${ }^{5}$. The black necrotic lesions could be misinterpreted as active vasculitis in some patients under immunosuppressants and hence we suggest the importance of considering phaeohyphomycosis and obtaining appropriate histology.

\section{REFERENCES}

1. Ng CY, de Hoog S, Li HE, Lee YY, Chen CB, Sun PL. Cutaneous Exophiala oligosperma infection in a patient with bullous pemphigoid with a review of the literature. Mycopathologia 2017;182:539-47.

2. Rimawi BH, Rimawi RH, Mirdamadi M, Steed LL, Marchell R, Sutton DA, et al. A case of Exophiala oligosperma successfully treated with voriconazole. Med Mycol Case Rep 2013;2:144-7.

3. Woo PC, Ngan AH, Tsang CC, Ling IW, Chan JF, Leung SY, et al Clinical spectrum of exophiala infections and a novel Exophiala species, Exophiala hongkongensis. J Clin Microbiol 2013;51:260-7.

4. Pena-Penabad C, Duran MT, Yebra MT, Rodriguez-Lozano J, Vieira $\mathrm{V}$, Fonseca E. Chromomycosis due to Exophiala jeanselmei in a renal transplant recipient. Eur J Dermatol 2003;13:305-7.

5. Gao L, Sun Y, He C, Zeng T, Li M. Synergistic effects of tacrolimus and azoles against Exophiala dermatitidis. Antimicrob Agents Chemother 2017;61: e00948-17.
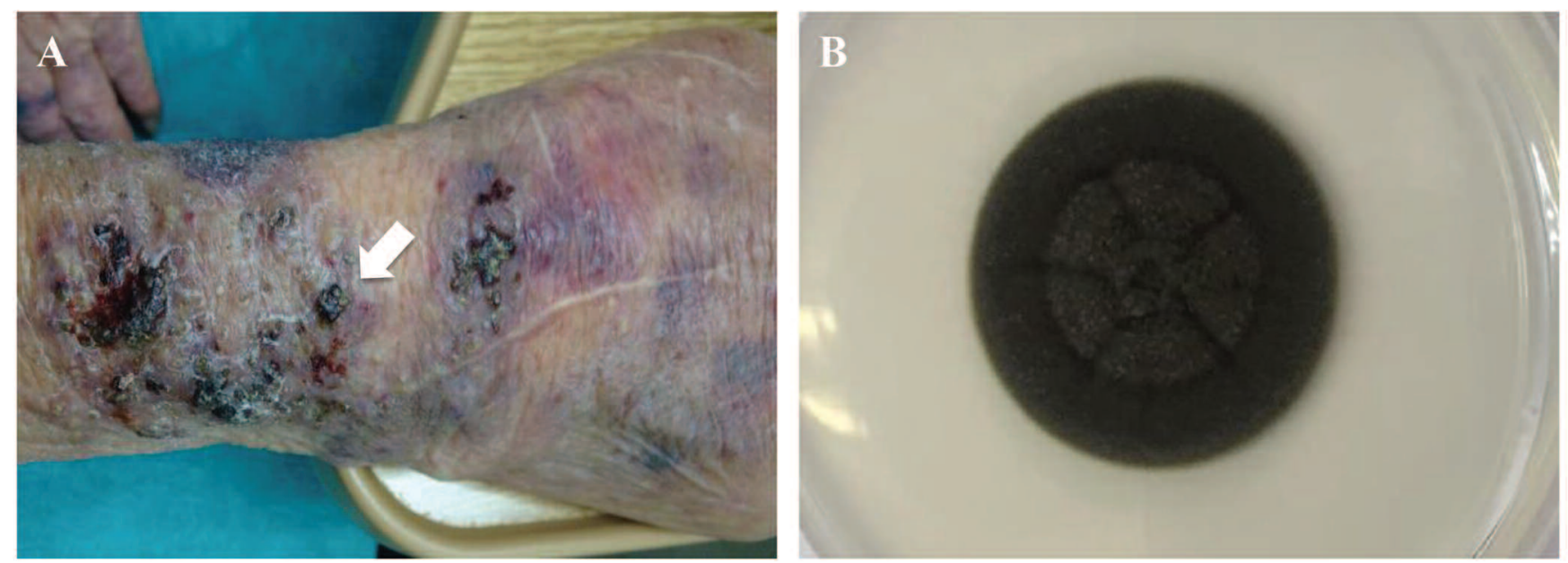

Figure 1. A. The gross appearance of the right forearm. Physical examination revealed cutaneous granulomatous lesions, indicating abscesses (white arrow). B. Pus samples were cultured on potato dextrose agar medium at $28^{\circ} \mathrm{C}$, producing olivaceous black colonies in 5 days. 